\title{
Photosynthetic Capacity and Water Use Efficiency in Sugarcane Genotypes Subject to Water Deficit During Early Growth Phase
}

\author{
Marcelo de Almeida Silva ${ }^{1 *}$, John Lonfover Jifon ${ }^{2}$, Claudiana Moura dos Santos ${ }^{1}$, Cleber \\ Junior Jadoski ${ }^{1}$ and Jorge Alberto Gonçalves da Silva ${ }^{2}$ \\ ${ }^{I}$ Departamento de Produção e Melhoramento Vegetal; Faculdade de Ciências Agronômicas; Universidade \\ Estadual Paulista; Botucatu - SP - Brasil. ${ }^{2}$ Texas A\&M AgriLife Research Center; Texas A\&M University System; \\ Weslaco - TX - USA.
}

\begin{abstract}
The objective of this study was to compare the gas exchange, photosynthetic capacity and water potential of sugarcane genotypes cultivated under water deficit conditions imposed during the initial growth phase. Experiments were performed in a greenhouse using two sugarcane genotypes namely: HoCP93-776 (drought susceptible) and TCP02-4587 (drought tolerant). Sixty days after planting, two different water treatments were applied (i.e., with or without water deficit). At 0,30 and 60 days after the treatment, gas exchange variables were evaluated for their relationship with water use, intrinsic instantaneous water use efficiency and instantaneous carboxylation efficiency. The SPAD index, photosynthetic pigments, water potential and relative water content in the leaves were also analyzed. The genotype HoCP93-776 was more sensitive to drought treatment as indicated by the significantly lower values of SPAD index, photosynthetic pigments, water potential $\left(\Psi_{w}\right)$ and relative water content $(R W C)$ variables. The genotype TCP02-4587 had higher water potential, stomatal control efficiency, water use efficiency $(W U E)$, intrinsic instantaneous water use efficiency (WUE $\left.E_{\text {intr }}\right)$, instantaneous carboxylation efficiency and photosynthetic capacity. The highest air vapor pressure deficit during the drought conditions could be due to the stomatal closing in the HoCP93-776, which contributed to its lower photosynthetic capacity.
\end{abstract}

Key words: Saccharum spp., photosynthesis, stomatal conductance, chlorophyll, drought tolerance, water potential

\section{INTRODUCTION}

Water deficit is a common problem in the majority of sugarcane production regions worldwide (Hemaprabha et al. 2004; Gilbert et al. 2011). The lack of adequate water supply leads to a substantial negative impact on the growth and development of plants, which reduces crop production and causes socio-economic damages.

Sugarcane (Saccharum spp.) is a globally important crop used in the production of $60 \%$ of the world's sugar as well as for the production of bioethanol and energy generation (Amalraj et al. 2010). This crop has been cultivated in a region between the $35^{\circ}$ parallels north and south of the equator, which includes both tropical and subtropical regions (Silva et al. 2010). In many of these areas, especially in the arid and semi-arid regions, rainfall does not provide the amount of water required by the sugarcane. Therefore, water deficit is one of the most important limiting factors for obtaining high production indices of sugarcane.

*Author for correspondence: marcelosilva@fca.unesp.br 
Studies related to drought tolerance in sugarcane crops have focused on agronomic and physiological characteristics that may be able to assist in the development and adaptation of new genotypes that are able to withstand adverse conditions (Hemaprabha et al. 2004; Silva et al. 2008; Rodrigues et al. 2009; Jangpromma et al. 2010a). These solutions can be complex because they are dependent on the plant's genotype, the stage of plant development and the duration and severity of the stress. Out of the four phenological stages in sugarcane, the tillering and grand growth phases, also known as the formation phases, have been identified as the critical periods of water demand (Ramesh and Mahadevaswany 2000). Therefore, during this time period, the damage caused by water deficit is most harmful to crop production.

As a C4 plant, sugarcane possesses high photosynthetic efficiency at elevated light saturation (McCormick et al. 2008).

Carbohydrates are produced via the process of photosynthesis. These carbohydrates are used in the plant's dry structural material and accumulate in the form of sugars in the stem, directly reflecting the economic profit of the crop (McCormick et al. 2008). However, photosynthesis is particularly sensitive to water deficit because the stomata close to conserve water, reducing $\mathrm{CO}_{2}$ diffusion to the fixation sites in the leaf mesophyll in the vicinity of the enzyme ribulose 1,5-bisphosphate carboxylase/oxygenase (Rubisco), which causes diminished photosynthesis and, consequently, reduced productivity (Lawlor and Tezara 2009; Ghannoum et al. 2009; Galmés et al. 2011). Thus, tradeoffs exist between water conservation and the $\mathrm{CO}_{2}$ assimilation rate for carbohydrate production.

Plants have developed physiological mechanisms that result in saving water for later periods. Stomatal closing is the first line of defense against dehydration. Plants that possess better control of stomatal function are more drought tolerant. In fact, stomata can be regulated based on the level of water deficit by only partially closing, leading to some carbon fixation during drought conditions and an increase in the efficiency of water use (Yordanov et al. 2000; Lawlor and Tezara 2009).

The ability of sugarcane to maintain key physiological processes, such as photosynthesis during moderate drought stress, is indicative of its potential to support productivity in a water-scarce environment (Silva et al. 2007; Centritto et al.
2009; Galmés et al. 2011). In previous studies, the efficiency of gas exchange in the plants possessing higher photosynthetic capacity, higher capacity in the efficiency of water use and higher intrinsic water use efficiency has been positively correlated with the maintenance of productivity during drought periods in a variety of crops, including sugarcane (Machado et al. 2009; Silva and Costa 2009), soybean (Gilbert et al. 2011), rice (Centritto et al. 2009) and wheat (Monneveux et al. 2006). These species have been widely studied to determine the characteristics of efficient genotypes for water use or drought tolerance.

Besides stomatal closure, non-stomatal limitations on photosynthesis and growth also occur during the periods of water scarcity. These qualities can help in the physiological understanding of sugarcane. Studies on the maximum quantum efficiency of photosystem II, the $F_{v} / F_{m}$ ratio (variable to maximal fluorescence), which reflects the maximum efficiency of the light absorbed by the antenna complex of photosystem II that is converted into chemical energy (Maxwell and Johnson 2000), has proven to be a good physiological reference to diagnose the integrity of the photosynthetic system in sugarcane during water deficit (Silva et al. 2007; Graça et al. 2010; Silva et al. 2011). As selection criteria for the screening of genotypes that display improved drought adaptation, studies in sugarcane have used the relative water content of the leaf (Rodrigues et al. 2009), the leaf water potential (Endres et al. 2010), estimates of the leaf chlorophyll content (Silva et al. 2011) and photosynthetic pigments (Jangpromma et al. 2010b).

A study of what occurs in the physiology of plants that grow under extreme conditions may contribute to both an increased efficiency and economic value of the crops. Understanding the relationship of water to the physiological response of sugarcane during drought conditions is strategically important because these data can be used to genetically improve the drought tolerance. The aim of this work was to comparatively study the gas exchange responses, photosynthetic capacity and water potential in two sugarcane genotypes cultivated under water deficit conditions during their initial growth phase.

\section{MATERIAL AND METHODS}

\section{Plant material and growth conditions}


The experiments were conducted in a greenhouse in the Department of Plant Physiology at Texas AgriLife Research, Texas A\&M University System, Weslaco, TX, USA $\left(26^{\circ} 12^{\prime} \mathrm{N}\right.$ and $97^{\circ} 57^{\prime}$ $\mathrm{W}$, at an altitude of $22.90 \mathrm{~m}$ ). Two sugarcane genotypes used were the HoCP93-776 (drought susceptible) and TCP02-4587 (drought tolerant) genotypes, which were chosen based on the data from the North American programs of crop genetic improvement. Buds were obtained from the healthy stalks and dispersed in 19-L pots with inert substrate mixed with $50 \mathrm{~g}$ of Osmocote (14-14-14) fertilizer (Carolina Biological Supply Co., Burlington, NC, USA). Three mini stalks with individual buds of each cultivar were planted per pot. These were later thinned to leave only one plant per pot. In this remaining plant, the primary stalk was maintained to eliminate the effects of tillering varieties and uneven occupation of the pots. During the experiment, the average air temperature was $27.4 \pm 5^{\circ} \mathrm{C}$, the daily average relative humidity was $62.8 \%$ and the daily average photosynthetically active radiation was $800 \mu \mathrm{mol}$ $\mathrm{m}^{-2} \mathrm{~s}^{-1}$. Until 60 days after the planting (DAP), all the pots received the same quantity of water to allow for proper plant development. At 60 DAP, the treatments were initiated (i.e., with or without water deficit). In treatment $\mathrm{W}$ (water treatment), the plants were hydrated with a quantity of water necessary to maintain the ideal moisture level in the substrate, which was approximately $22 \%$ (corresponding to $100 \%$ capacity for the pots' water retention). In treatment $\mathrm{D}$ (drought conditions), the plants were maintained at $50 \%$ of the moisture level used in treatment W. Using an $\mathrm{ECH}_{2} \mathrm{O}$ soil moisture sensor (Decagon, Washington, USA), the moisture levels were monitored two times a day (i.e., in the morning and the afternoon) by inserting the $10 \mathrm{~cm}$ dielectric Echo Check sensors (Decagon, Washington, USA) into each pot. The experimental design was entirely randomized in a $2 \times 2$ factorial: two genotypes and two water regimens (without deficiency $=\mathrm{W}$ and with deficiency $=D$ ), in four replicates. Three time points were evaluated: 0,30 and 60 days after treatments (DAT).

\section{Gas exchange measurements}

The measurements for gas exchange were recorded between 8:00 and 10:00 AM in the medium portion of leaf +1 completely expanded. These evaluations were completed with an infrared, portable $\mathrm{CO}_{2}$ gas analyzer (ADC, BioScientific Ltd., Hoddesdon, UK). The photosynthesis rate, transpiration, stomatal conductance, intracellular $\mathrm{CO}_{2}$ concentration and leaf to air vapor pressure deficit $\left(\mathrm{VPD}_{\text {leaf-air }}\right)$ were all evaluated. Using the photosynthesis (Pn), transpiration (E), stomatal conductance (gs) and leaf intercellular $\mathrm{CO}_{2}$ concentration $(\mathrm{Ci})$ values. Relationship were calculated the instantaneous water use efficiency WUE $\left(\mu \mathrm{mol} \mathrm{mol}^{-1}\right)$ was calculated as $\mathrm{Pn} / \mathrm{E}$, the instantaneous intrinsic water use efficiency $\mathrm{WUE}_{\text {intr }}\left(\mu \mathrm{mol} \mathrm{mol}^{-1}\right)$, was calculated as $\mathrm{Pn} / \mathrm{gs}$ and the instantaneous carboxylation efficiency $(\mathrm{Pn} / \mathrm{Ci})$.

\section{Fluorescence analysis of chlorophyll $a$}

The photochemical efficiency of photosynthesis was obtained from the fluorescent analysis of chlorophyll $a$. The measurements were made on the same leaves that were evaluated for gas exchange. The maximum photochemical efficiency $(F v / F m)$ readings of photosystem II were determined using a portable modulated fluorescence measurer (Opti-Sciences, Incorporation, Hudson, $\mathrm{NH}$, USA) after adapting the leaves to the dark for $30 \mathrm{~min}$ via special leaf clips. The readings were made after saturating $1 \mathrm{~s}$ light pulses to promote the closing of the photosystem II reaction centers, according to the method described by Maxwell and Johnson (2000).

\section{Measuring chlorophyll content via SPAD reading and spectrophotometry}

An estimation of the chlorophyll content was determined using a SPAD-502 chlorophyll meter (Minolta Corp., Ramsey, NJ, USA). An average of three readings in leaf +2 of each plant was used. The soil plant analysis development (SPAD index) reading corresponded to the green color content in the leaf, and its value was equivalent to the amount of light transmitted by the leaf in two regions of the red and infrared wavelengths. The quantity of red light absorbed indicated the quantity of chlorophyll, whereas the quantity of light absorbed next to the infrared wavelength served as an internal reference to compensate for leaf thickness (Torres Netto et al. 2005). After all the SPAD index were completed, the leaves +2 were collected, placed in plastic bags and kept refrigerated for future analysis of the leaf pigments. The chlorophyll $a$, chlorophyll $b$ contents, and total chlorophyll were obtained 
according to the method described by Lichtenthaler (1987). Briefly, chlorophyll extract was obtained from $0.69 \mathrm{~cm}^{2}$ leaf discs, incubated in $2 \mathrm{~mL}$ of $\mathrm{N}, \mathrm{N}$-dimethylformamide (DMF), and an absorbance reading was performed using spectrophotometry at wavelengths of 480 and 647 $\mathrm{nm}$.

\section{Water potential and relative water content in the leaf}

Leaf water potential $\left(\Psi_{\mathrm{w}}\right)$ was evaluated between 8:00 and 10:00 AM using a Scholander pressure chamber (Soil Moisture Equipment, Santa Barbara, CA, USA). The reading was determined at the extremity (tip) of leaf +2 of the primary tiller. Pressure was applied until exudation occurred from the cut made in the leaf petiole. Leaf relative water contents were calculated according to the methods of Jamaux et al. (1997). Leaf discs were collected $\left(0.69 \mathrm{~cm}^{2}\right)$ from each pot in leaf +2 to determine the fresh mass. The turgid mass was obtained after $24 \mathrm{~h}$ of rehydrating with distilled water at $4^{\circ} \mathrm{C}$. The dry mass was obtained after the discs were dried at $80^{\circ} \mathrm{C}$ for $48 \mathrm{~h}$. Based on the fresh weight $(\mathrm{FW})$, dry weight (DW) and turgid weight (TW) of leaf discs, the relative water content (RWC) was calculated using the following formula: RWC $=(\mathrm{FW}-\mathrm{DW} / \mathrm{TW}-\mathrm{DW}) \times 100$.

\section{Statistical analyses}

The experimental data were subjected to the analysis of variance ( $\mathrm{F}$ test), and the averages were compared using Tukey's test with a 5\% probability cutoff. The Pearson correlation ( $r$ ) was used (Brussab and Morettin 1986) to verify the relation between the gas exchange variables, chlorophyll $a$ fluorescence, photosynthetic pigments, the leaf water potential and the RWC of the study period.

\section{RESULTS}

Gas exchange responses differed between the two genotypes in both the well-watered plants and those subjected to water deficit. The leaf to air vapor pressure deficit $\mathrm{VPD}_{\text {(leaf-air) }}$ values at the initiation of stress were low, with averages values of $1.6 \mathrm{kPa}$ for TCP02-4587 and $1.4 \mathrm{kPa}$ for HoCP93-776 (Fig. 1A). Figure 1B showed the time point at which the highest stomatal conductance values were recorded. The increased vapor pressure was identified in both the genotypes during the water deficit period, with varying levels at 30 and 60 DAT from 2.5 to 2.8 $\mathrm{kPa}$ for the HoCP93-776 genotype and from 2.5 to $2.3 \mathrm{kPa}$ for the TCP02-4587 genotype (Fig. 1A).

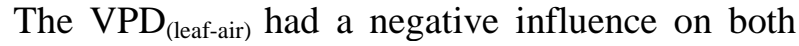
the stomatal conductance $(\mathrm{r}=-0.77 * *)$ and photosynthesis in the HoCP93-776 genotype during water deficit (Table 1), which thus demonstrated higher stomatal sensitivity to VPD (leaf-air). VPD (leaf-air) also displayed an inverse correlation with water potential $\left(\Psi_{\mathrm{w}}\right)$ and $\mathrm{RWC}$ (Table 1). Conversely, these correlations were not observed in the TCP02-4587 genotype, which suggested that the VPD (leaf-air) had little effect on the physiological processes in this genotype. The stomatal conductance values from the initial phase to day 30 of water deficit decreased less for TCP02-4587, from $0.25 \mathrm{~mol} \mathrm{~m}^{-2} \mathrm{~s}^{-1}$ to $0.11 \mathrm{~mol} \mathrm{~m}^{-2}$ $\mathrm{s}^{-1}$, compared to HoCP93-776, which changed from $0.38 \mathrm{~mol} \mathrm{~m}^{-2} \mathrm{~s}^{-1}$ to $0.06 \mathrm{~mol} \mathrm{~m}^{-2} \mathrm{~s}^{-1}$ (Fig. 1B). At day 60 of drought, similar stomatal conductance values were observed in both the genotypes. The average stomatal conductance value was close to $0.10 \mathrm{~mol} \mathrm{~m}^{-2} \mathrm{~s}^{-1}$ for both the genotypes (Fig. 1B).

Transpiration displayed maximum values of approximately $4.6 \mathrm{mmol} \mathrm{m} \mathrm{m}^{-2} \mathrm{~s}^{-1}$ in the wellhydrated plants of the two tested genotypes (Fig. 1C). After 30 days of water deficit, there was reduced transpiration for both the genotypes. The HoCP93-776 genotype showed an average value of $1.3 \mathrm{mmol} \mathrm{m}^{-2} \mathrm{~s}^{-1}$ and the TCP02-4587 genotype had a value of $2.3 \mathrm{mmol} \mathrm{m} \mathrm{s}^{-1}$. Therefore, the HoCP93-776 and TCP02-4587 genotypes displayed reductions of 64 and $42 \%$ in relation to 0 DAT, respectively. These values remained stable until the end of the experiment. For both the genotypes tested, transpiration was positively correlated with stomatal conductance during drought conditions and displayed no correlation with the $\operatorname{VPD}_{\text {(leaf-air) }}$ (Table 1). Therefore, the stomatal conductance began to have a greater effect on transpiration than the $\mathrm{VPD}_{\text {(leaf-air) }}$ during water deficit.

Net photosynthesis followed similar trends as stomatal conductance and transpiration rates. The average photosynthesis rates at the start of the water treatments were $29.42 \mu \mathrm{mol} \mathrm{m} \mathrm{m}^{-2} \mathrm{~s}^{-1}$ for TCP02-4587 and $30.75 \mu \mathrm{mol} \mathrm{m}{ }^{-2} \mathrm{~s}^{-1}$ for HoCP93776 (Fig. 1D). At 30 DAT, 52.6 and 79\% reductions were observed in the TCP02-4587 and HoCP93-776 genotypes, respectively during water deficit. Photosynthetic rates were recorded at 14 $\mu \mathrm{mol} \mathrm{m} \mathrm{m}^{-2}$ and $6.5 \mu \mathrm{mol} \mathrm{m} \mathrm{s}^{-2}$ for TCP02-4587 
and HoCP93-776, respectively. These values remained nearly constant until 60 DAT. These results demonstrated that the TCP02-4587 genotype had greater $\mathrm{CO}_{2}$ assimilation throughout the water deficit period. The TCP02-4587 genotype could be identified by its correlations with gs and E compared to HoCP93-776. During water deficit, the correlation between the photosynthesis and stomatal conductance of TCP02-4587 was significant $\left(r=0.96^{* *}\right)$, while HoCP93-776 had a correlation of $\mathrm{r}=0.92^{* *}$. The photosynthesis and transpiration correlation values were $\mathrm{r}=0.93^{* *}$ for TCP02-4587 and $\mathrm{r}=0.85^{* *}$ for HoCP93-776 (Table 1).
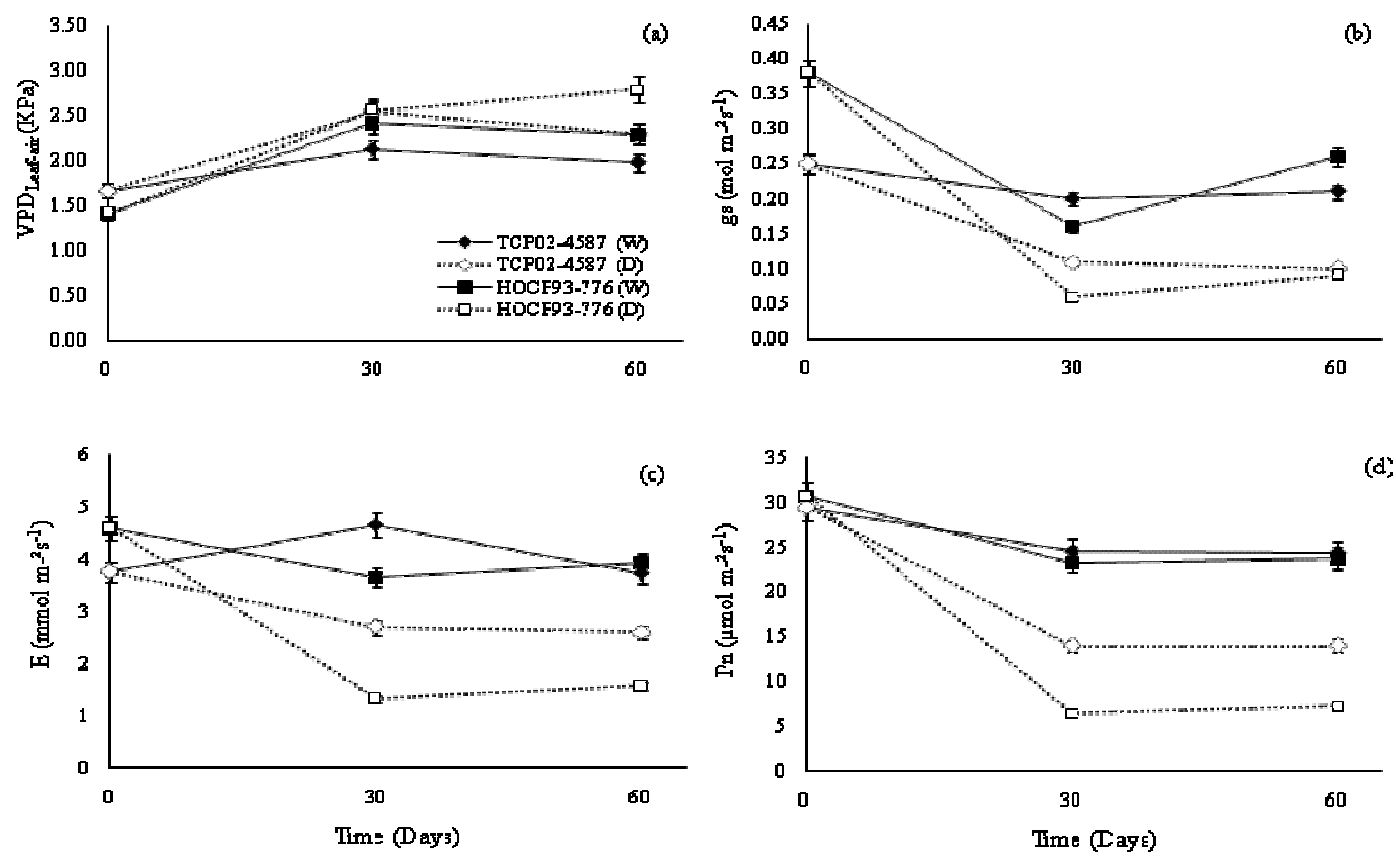

Figure 1 - Mean diurnal variations of vapor pressure deficit (a), stomatal conductance (b), transpiration (c) and photosynthesis rate (d) of two sugarcane genotypes under two water regimes (W, well-watered and $\mathrm{D}$, water deficiency) measured at 0,30 and 60 days after treatment imposition (DAT). Each point represents the mean of four plants, and bars indicate standard error.

Figure $2 \mathrm{~A}$ illustrated that both the genotypes did not exhibit a difference in the internal $\mathrm{CO}_{2}$ concentration (i.e., they maintained similar values at days 30 and 60 of water deficit). However, the HoCP93-776 genotype had a $\mathrm{Ci}$ measurement of $142 \mu \mathrm{mol} \mathrm{mol}{ }^{-1}$, and TCP02-4587 had a Ci value of $157.33 \mu \mathrm{mol} \mathrm{mol}{ }^{-1}$. Therefore, as the plant age increased, water deficit limited the increase of the internal $\mathrm{CO}_{2}$ concentration.

The maximum reduction in carboxylation efficiency $(\mathrm{Pn} / \mathrm{Ci})$ was at 30 days of water deficit, which resulted in a reduction of $62 \%$ in the HoCP93-776 genotype and 25\% in TCP02-4587 (Fig. 2B). This reduction was maintained until 60 days, therefore, plants were more efficient at carboxylation during the 30 - to 60 -day period. The TCP02-4587 genotype displayed a positive correlation of the carboxylation efficiency with photosynthesis and stomatal conductance and a negative correlation with $\mathrm{Ci}$ (Table 1). This suggested that the maintenance of the internal $\mathrm{CO}_{2}$ concentration during water deficit was associated with higher carboxylation efficiency. In the HoCP93-776 genotype, assimilation/leaf intercellular $\mathrm{CO}_{2}$ concentration $(\mathrm{Pn} / \mathrm{Ci})$ correlated positively with photosynthesis $(\mathrm{r}=0.77 * *)$ and stomatal conductance $\left(\mathrm{r}=0.63^{* *}\right)$.

The instantaneous efficiency of water use (WUE) during the entire water deficit period exhibited an expressive reduction in the HoCP93-776 genotype, from 6.7 to $3.9 \mathrm{~mol} \mathrm{mmol}^{-1}$ (Fig. 2C), while the TCP02-4587 genotype displayed little variation, from 7.9 to $6.5 \mathrm{~mol} \mathrm{mmol}^{-1}$. These values were also observed in irrigated plants, therefore, a greater capacity for the plants to maintain their water usage was observed during the drought period. 

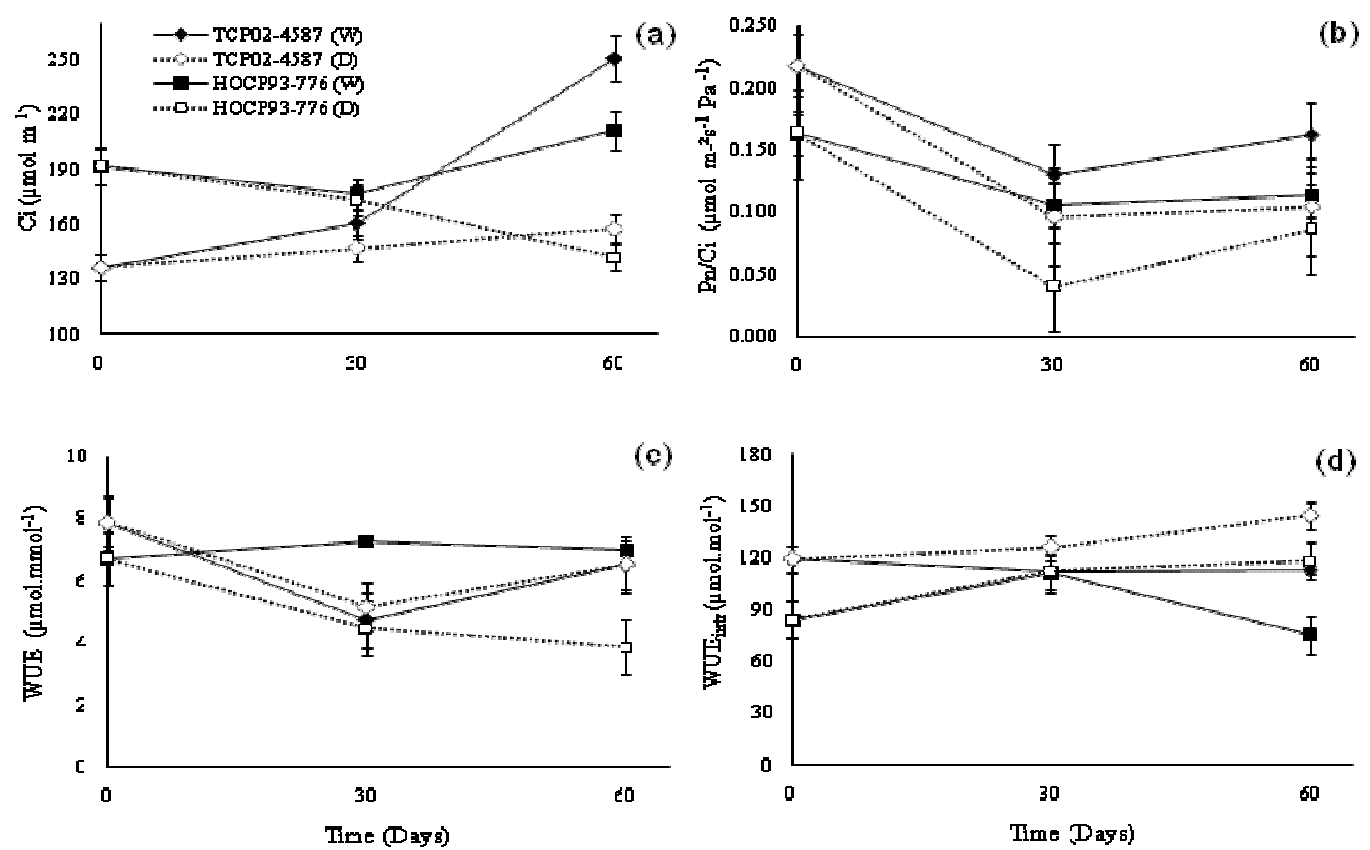

Figure 2 - Mean internal concentration of $\mathrm{CO}_{2}$ (a), instantaneous carboxilation efficiency (b), instantaneous water use efficiency (c), intrinsic water use efficiency (d) of two sugarcane genotypes under two water regimes (W, well-watered and D, water deficiency) measured at 0,30 and 60 days after treatment imposition (DAT). Each point represents the mean of four plants, and bars indicate standard error.

Table 1 - Pearson's correlation coefficients for association among gas exchange ( $\mathrm{Pn}, \mathrm{Ci}, \mathrm{VPD}$ (leaf-air), gs, E, Pn/Ci, WUE, WUE $E_{\text {intr }}$ ), water potential $(\Psi \mathrm{w})$ and leaf relative water content $(\mathrm{RWC})$ of two sugarcane genotypes under water deficiency regime.

\begin{tabular}{|c|c|c|c|c|c|c|c|c|c|}
\hline Variable & $\mathbf{C i}$ & VPD $_{\text {(leaf-air) }}$ & gs & $\mathbf{E}$ & $\mathbf{P n} / \mathbf{C i}$ & WUE & WUE $_{\text {intr }}$ & $\Psi \mathbf{w}$ & RWC \\
\hline \multicolumn{10}{|c|}{ HoCP93-776 under drought } \\
\hline $\mathrm{Pn}$ & 0.27 & $-0.74 * *$ & $0.92 * *$ & $0.85^{* *}$ & $0.77 * *$ & $0.63 *$ & $-0.57 *$ & $0.74 * *$ & 0.51 \\
\hline $\mathrm{Ci}$ & & -0.55 & 0.53 & 0.28 & -0.08 & 0.12 & $-0.85^{* *}$ & 0.23 & 0.33 \\
\hline $\mathrm{VPD}_{\text {(leaf-air) }}$ & & & $-0.77 * *$ & -0.46 & -0.27 & $-0.84 * *$ & $0.67 *$ & $-0.74 * *$ & $-0.70 * *$ \\
\hline gs & & & & $0.83 * *$ & $0.63 * *$ & 0.50 & $-0.77 * *$ & $0.67 * *$ & 0.49 \\
\hline $\mathrm{E}$ & & & & & $0.92 * *$ & 0.17 & $-0.66^{*}$ & 0.39 & 0.09 \\
\hline $\mathrm{Pn} / \mathrm{Ci}$ & & & & & & 0.16 & -0.33 & 0.28 & -0.05 \\
\hline WUE & & & & & & & -0.19 & $0.75 * *$ & $0.75^{* *}$ \\
\hline WUE $_{\text {intr }}$ & & & & & & & & -0.40 & -0.30 \\
\hline$\Psi_{\mathrm{w}}$ & & & & & & & & & $0.91 * *$ \\
\hline \multicolumn{10}{|c|}{ TCP02-4587 under drought } \\
\hline $\mathrm{Pn}$ & -0.37 & -0.30 & $0.96 * *$ & $0.93 * *$ & $0.89 * *$ & $0.88 * *$ & -0.42 & $0.80 * *$ & $0.74 * *$ \\
\hline $\mathrm{Ci}$ & & 0.158 & -0.18 & -0.29 & $-0.65^{*}$ & -0.44 & -0.39 & -0.35 & -0.16 \\
\hline $\mathrm{VPD}_{\text {(leaf-air) }}$ & & & -0.27 & -0.26 & -0.27 & -0.31 & 0.042 & -0.09 & -0.01 \\
\hline gs & & & & $0.95 * *$ & $0.82 * *$ & $0.77 * *$ & $-0.61 * *$ & $0.77 * *$ & $0.81 * *$ \\
\hline $\mathrm{E}$ & & & & & $0.90^{* *}$ & $0.66^{* *}$ & $-0.56^{*}$ & $0.78 * *$ & $0.84 * *$ \\
\hline $\mathrm{Pn} / \mathrm{Ci}$ & & & & & & $0.71 * *$ & -0.28 & $0.79 * *$ & $0.73 * *$ \\
\hline WUE & & & & & & & -0.12 & $0.67 *$ & 0.45 \\
\hline WUE $_{\text {intr }}$ & & & & & & & & -0.54 & $-0.75 * *$ \\
\hline$\Psi_{\mathrm{w}}$ & & & & & & & & & $0.88 * *$ \\
\hline
\end{tabular}

Significance $(* P<0.05$ and $* * P<0.01)$ 
In the TCP02-4587 genotype, the WUE ratio was positively correlated with photosynthesis $\left(0.88^{* *}\right)$, $\Psi_{\mathrm{w}}\left(0.80^{* *}\right), \quad \mathrm{RWC}(0.74 * *)$ and stomatal conductance $\left(\mathrm{r}=0.77^{* *}\right)$ (Table 1$)$, indicating that this genotype exhibited better maintenance of water status in the leaf without any loss in gas exchange. The HoCP93-776 genotype also displayed a positive correlation of WUE with photosynthesis $\left(r=0.63^{*}\right)$ and $\Psi_{\mathrm{w}}\left(\mathrm{r}=0.75^{* *}\right)$ and an inverse correlation with $\operatorname{VPD}_{\text {(leaf-air) }}(\mathrm{r}=$ $0.84^{* *}$ ) (Table 1). This reconfirmed its higher susceptibility to $\mathrm{VPD}_{\text {(leaf-air) }}$ during the drought period.

For the intrinsic efficiency of water use $\left(\mathrm{WUE}_{\text {intr }}\right)$, during the initial period when both the plant genotypes were hydrated, the $\mathrm{WUE}_{\text {intr }}$ values were smaller, with averages of $84.2 \mu \mathrm{mol} \mathrm{mol}{ }^{-1}$ for HoCP93-776 and $119.5 \mu \mathrm{mol} \mathrm{mol}^{-1}$ for TCP024587. After 60 days of water deficit, the genotypes displayed $\mathrm{A} / \mathrm{gs}$ averages of $118.3 \mu \mathrm{mol} \mathrm{mol}{ }^{-1}$ and $144.4 \mu \mathrm{mol} \mathrm{mol}^{-1}$ for HoCP93-776 and TCP024587, respectively (Fig. 2C). The $\mathrm{WUE}_{\text {intr }}$ increase was due to the large gs reduction caused by stomatal closing, which increased photosynthesis. This could be explained by the inverse correlation of $\mathrm{WUE}_{\text {intr }}$ with the stomatal conductance observed in HoCP93-776 ( $\mathrm{r}=-0.77 * *)$ and TCP02-4587 ( $\mathrm{r}=-0.61 * *)$ (Table 1$)$. In the HoCP93-776 genotype, the $\mathrm{WUE}_{\text {intr }}$ ratio also displayed an inverse relationship with photosynthesis $\left(\mathrm{r}=-0.57^{*}\right)$ and a positive relationship with $\operatorname{VPD}($ leaf-air) $(r=0.67 *)$ (Table 1). For both the genotypes, there was little reduction in the maximum photochemical efficiency of photosystem II during the water deficit period (Fig. 3). During the entire period, the $\mathrm{Fv} / \mathrm{Fm}$ relation varied in the TCP02-4587 genotype from 0.82 to 0.78 , while the HoCP93-776 genotype varied from 0.82 to 0.77 (Fig. 3). This suggested that both the genotypes maintained highly efficient use of excitation energy in the photochemical process during the stress. There was a positive correlation between the photosynthetic activity and $F v / F m$ for HoCP93-776 $\left(\mathrm{r}=0.85^{* *}\right)$ and TCP02$4587\left(\mathrm{r}=0.90^{* *}\right)$ (Table 2).

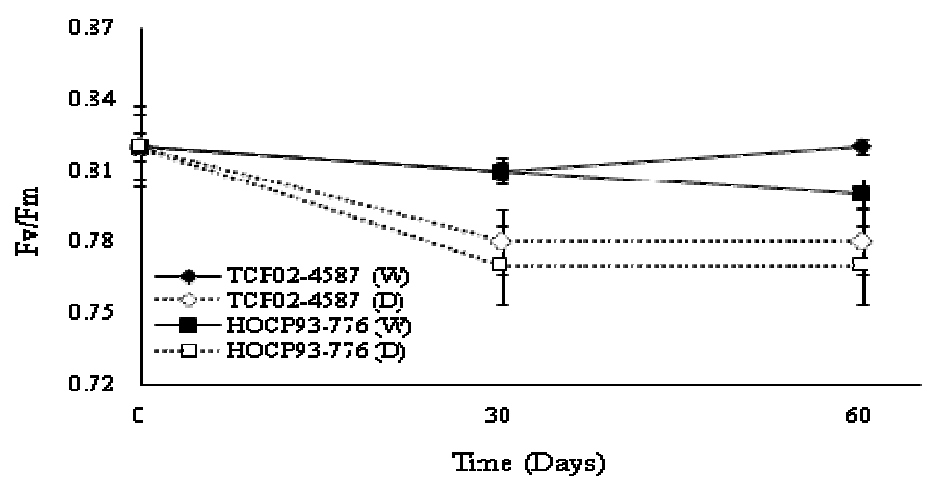

Figure 3 - Mean maximum quantum yield of photosystem II $\left(F_{\mathrm{v}} / F_{\mathrm{m}}\right)$ of two sugarcane genotypes under water regimes (W, well-watered and $\mathrm{D}$, water deficiency) measured at 0,30 and 60 days after treatment imposition (DAT). Each point represents the mean of four plants, and bars indicate standard error.

Table 2 - Pearson's correlation coefficients for association among chlorophyll fluorescence $\left(F_{\mathrm{v}} / F_{\mathrm{m}}\right)$, photosynthesis (Pn), estimated chlorophyll content (SPAD index), chlorophyll $a, b$ and total (Chl $a$, Chl $b$ and Chl total) of two sugarcane genotypes under water deficiency regime.

\begin{tabular}{|c|c|c|c|c|c|c|c|c|c|c|}
\hline Variable & Pn & $\begin{array}{l}\text { SPAD } \\
\text { index }\end{array}$ & Chl $a$ & Chl $b$ & ChlTotal & Pn & $\begin{array}{l}\text { SPAD } \\
\text { index }\end{array}$ & Chl $a$ & Chl $b$ & ChlTotal \\
\hline & \multicolumn{5}{|c|}{ HoCP93-776 under drought } & \multicolumn{5}{|c|}{ TCP02-4587 under drought } \\
\hline$F_{\mathrm{v}} / F_{\mathrm{m}}$ & $0.85^{* *}$ & $0.61 *$ & $0.79 * *$ & 0.49 & $0.71 * *$ & $0.90 * *$ & 0.19 & $0.67 * *$ & 0.33 & $0.64 *$ \\
\hline $\mathrm{Pn}$ & & $0.54 *$ & $0.91 * *$ & $0.74 * *$ & $0.93 * *$ & & $0.17 *$ & $0.66 *$ & 0.29 & $0.60 *$ \\
\hline SPAD index & & & $0.71 * *$ & 0.26 & $0.68 *$ & & & 0.36 & 0.34 & 0.36 \\
\hline Chl $a$ & & & & $0.65^{*}$ & 0.99 & & & & $0.84 * *$ & 0.99 \\
\hline Chl $b$ & & & & & $0.73 * *$ & & & & & $0.90 *$ \\
\hline
\end{tabular}

Significance $(* P<0.05$ and $* * P<0.01)$ 
Significant differences were observed between the two genotypes in the estimated levels of chlorophyll and photosynthetic pigments (Table 3 ). At the beginning of the experiment, both the genotypes had average chlorophyll content indices of about 40 (SPAD index). At days 30 and 60 of water deficit, the TCP02-4587 genotype remained close to 40 (SPAD index); however, the HoCP93776 genotype had lower values, with chlorophyll content averages from 36.02 to 30.62 (SPAD index), showing a reduction of 14.7 and $23.5 \%$, respectively. These results suggested that the TCP02-4587 genotype displayed higher chlorophyll synthesis capacity, and therefore, a higher intensity of green color, even during water deficit conditions.

Independent of the treatment, the TCP02-4587 genotype displayed higher photosynthetic pigment values. After 30 days of water deficit in the TCP02-4587 genotype, a reduction of chlorophyll $a$, chlorophyll $b$ and total chlorophyll of 20, 20 and $20.3 \%$, respectively was observed. For the HoCP93-776 genotype, the reduction of chlorophyll $a$, chlorophyll $b$ and total chlorophyll was $42,25.3$ and $38.6 \%$, respectively (Table 3 ). At water deficit day 60 , the TCP02-4587 genotype maintained a lower reduction in the chlorophyll $a$ (22.6\%), chlorophyll $b(5.15 \%)$ and total chlorophyll (19.4\%) values compared with the control (Table 3). The HoCP93-776 plants displayed the largest decreases (i.e., $42 \%$ for chlorophyll $a, 7 \%$ for chlorophyll $b$ and $35 \%$ for total chlorophyll). Therefore, it could be concluded that the HoCP93-776 genotype exhibited chlorophyll degradation during the prolonged water deficit.

Table 3 - Estimated chlorophyll content (SPAD index), chlorophyll $a$, chlorophyll $b$ and chlorophyll total in two sugarcane genotypes water treatments (W, well-watered and D, water deficiency) measured on 0, 30 and 60 days after treatment imposition (DAT).

\begin{tabular}{|c|c|c|c|c|c|c|c|c|}
\hline \multirow{2}{*}{$\begin{array}{l}\text { Genotype } \\
0 \text { DAT }\end{array}$} & \multicolumn{2}{|c|}{$\begin{array}{c}\text { SPAD } \\
\text { (index) }\end{array}$} & \multicolumn{2}{|c|}{$\begin{array}{c}\text { Chl } a \\
\left(\mu \mathrm{g} \mathrm{cm} \mathrm{cm}^{2} \mathrm{FW}\right)\end{array}$} & \multicolumn{2}{|c|}{$\begin{array}{c}\text { Chl } b \\
\left(\mu \mathrm{g} \mathrm{cm} \text { cm }^{2} \mathrm{FW}\right)\end{array}$} & \multicolumn{2}{|c|}{$\begin{array}{c}\text { ChlTotal } \\
\left(\mu \mathrm{g} \mathrm{cm}^{2} \text { FW }\right)\end{array}$} \\
\hline & $\mathrm{W}$ & $\mathrm{D}$ & $\mathrm{W}$ & $\mathrm{D}$ & $\mathrm{W}$ & $\mathrm{D}$ & $\mathrm{W}$ & $\mathrm{D}$ \\
\hline ТCP02-4587 & $40.00 \mathrm{Aa}^{\dagger}$ & $40.0 \mathrm{Aa}$ & $23.79 \mathrm{Aa}$ & $23.79 \mathrm{Aa}$ & $5.76 \mathrm{Aa}$ & $5.76 \mathrm{Aa}$ & $29.56 \mathrm{Aa}$ & $29.56 \mathrm{Aa}$ \\
\hline НоСР93-776 & $42.10 \mathrm{Aa}$ & $40.0 \mathrm{Aa}$ & $17.59 \mathrm{Ba}$ & $18.59 \mathrm{Ba}$ & $4.27 \mathrm{Ba}$ & $4.77 \mathrm{Ba}$ & $21.86 \mathrm{Ba}$ & $23.36 \mathrm{Ba}$ \\
\hline $30 \mathrm{DAT}$ & $\mathrm{W}$ & $\mathrm{D}$ & $\mathrm{W}$ & $\mathrm{D}$ & $\mathrm{W}$ & $\mathrm{D}$ & $\mathrm{W}$ & $\mathrm{D}$ \\
\hline ТCP02-4587 & 51.37Aa & $40.10 \mathrm{Ab}$ & $27.31 \mathrm{Aa}$ & $21.75 \mathrm{Ab}$ & 7.54Aa & $6.02 \mathrm{Ab}$ & $34.86 \mathrm{Aa}$ & $27.78 \mathrm{Aa}$ \\
\hline НоСР93-776 & $41.27 \mathrm{Ba}$ & $36.02 \mathrm{Bb}$ & $17.55 \mathrm{Ba}$ & $10.12 \mathrm{Bb}$ & $4.87 \mathrm{Ba}$ & $3.64 \mathrm{Bb}$ & $22.43 \mathrm{Ba}$ & $13.76 \mathrm{Bb}$ \\
\hline $60 \mathrm{DAT}$ & $\mathrm{W}$ & $\mathrm{D}$ & $\mathrm{W}$ & $\mathrm{D}$ & $\mathrm{W}$ & $\mathrm{D}$ & $\mathrm{W}$ & $\mathrm{D}$ \\
\hline ТСР02-4587 & $46.95 \mathrm{Aa}$ & $40.00 \mathrm{Ab}$ & $22.59 \mathrm{Aa}$ & $17.48 \mathrm{Ab}$ & $5.04 \mathrm{Aa}$ & 4.78Aa & $27.64 \mathrm{Aa}$ & $22.26 \mathrm{Aa}$ \\
\hline НоСР93-776 & $40.00 \mathrm{Aa}$ & $30.62 \mathrm{Bb}$ & $18.03 \mathrm{Ba}$ & $10.42 \mathrm{Bb}$ & 4.71Aa & 4.38Aa & $22.75 \mathrm{Aa}$ & $14.80 \mathrm{Bb}$ \\
\hline Mean & \multicolumn{2}{|c|}{40.53} & \multicolumn{2}{|c|}{19.08} & \multicolumn{2}{|c|}{5.13} & \multicolumn{2}{|c|}{24.22} \\
\hline $\mathrm{CV} \%$ & \multicolumn{2}{|c|}{8.67} & \multicolumn{2}{|c|}{13.71} & \multicolumn{2}{|c|}{13.25} & \multicolumn{2}{|c|}{12.97} \\
\hline
\end{tabular}

$\dagger$ Means for each evaluation season in a same row and within a same attribute column and having the same letter (lower case), and in the same column between genotypes (upper case) are not significantly different at 0.05 probability level (Tukey's test).

No correlation was identified between the SPAD index and the photosynthetic pigments for the TCP02-4587 genotype subjected to water deficit (Table 2). However, a positive correlation was observed between the SPAD index and photosynthesis $\left(\mathrm{r}=0.17^{*}\right)$, chlorophyll $a$ with photosynthesis $\left(\mathrm{r}=0.66^{*}\right)$ and with $F v / F m(\mathrm{r}=$ $0.67^{* *}$ ). For the HoCP93-776 genotype, the SPAD values were positively correlated with chlorophyll $a\left(\mathrm{r}=0.71^{* *}\right)$, total chlorophyll $\left(\mathrm{r}=0.68^{*}\right)$, photosynthesis $(\mathrm{r}=0.54 *)$ and $F v / F m(\mathrm{r}=0.61 *)$. A strong correlation was also identified between chlorophyll $a$ and photosynthesis $\left(\mathrm{r}=0.91^{* *}\right)$ and with $F v / F m \quad(\mathrm{r}=0.79 * *)$ (Table 2). This demonstrated that water deficit caused more damage in the photosynthetic pigments in the HoCP93-776 genotype.

The average values initially reported for leaf water potential were -1.2 MPa for HoCP93-776 and -0.8 $\mathrm{MPa}$ for TCP02-4587 (Fig. 4A). Significant differences between the hydrated and nonhydrated plants were observed at day 30 of water deficit, with a reduction in the HoCP93-776 genotype to $-2.0 \mathrm{MPa}$, while the TCP02-4587 genotype reached $-1.5 \mathrm{MPa}$ (Fig. 4A). At day 60 of water shortage, the decrease in $\Psi_{\mathrm{w}}$ was more accentuated in the HoCP93-776 genotype, which reached -2.4 $\mathrm{MPa}$, whereas the TCP02-4587 genotype had a value of $-1.9 \mathrm{MPa}$. These values represented reductions of 46 and $26 \%$ in the 
HoCP93-776 and TCP02-4587 genotypes, respectively, when compared with the control.

The $\Psi_{\mathrm{w}}$ revealed that during water deficit, there was a significant inverse correlation with $\mathrm{VPD}_{\text {(leaf- }}$ air) for the HoCP93-776 genotype $(\mathrm{r}=-0.74 * *)$ and a positive correlation with stomatal conductance $(\mathrm{r}$ $=0.67 * *)$ and photosynthesis $(\mathrm{r}=0.67 * *)$ (Table 1). However, there was no influence on transpiration $(\mathrm{r}=0.39)$. Conversely, for the TCP02-4587 genotype, a positive relation was observed for $\Psi_{\mathrm{w}}$ with transpiration $\left(\mathrm{r}=0.78^{* *}\right)$, stomatal conductance $\left(\mathrm{r}=0.80^{* *}\right)$ and photosynthesis $(\mathrm{r}=0.77 * *)$ (Table 1). This demonstrated that the partial stomatal closure triggered by the stress was affected by leaf water potential.
Between day 1 and day 60 of water deficit treatments, the relative leaf water content varied from 90.2 to $77.8 \%$ in the HoCP93-776 genotype and from 92.5 to $83.8 \%$ in the TCP02-4587 genotype (Fig. 4B). Both the genotypes had a strong positive correlation of RWC with $\Psi_{\mathrm{w}}$ (HoCP93-776, $\mathrm{r}=0.91^{* *}$, TCP02-4587, $\mathrm{r}=0.88$ **) (Table 1). At the end of the experiment, a reduction of $12 \%$ in the RWC was recorded for the HoCP93-776 genotype and 7\% in the TCP02-4587 genotype. Therefore, the lowest reduction of $\Psi \mathrm{w}$ and RWC was in the TCP02-4587 genotype, which was a possible consequence of the maintenance of the leaves' turgor during fluctuations in the water available to the plant.

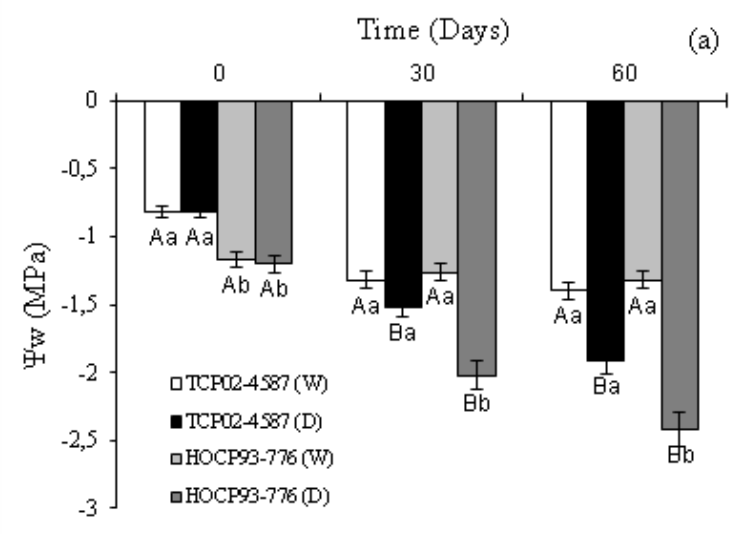

(a)

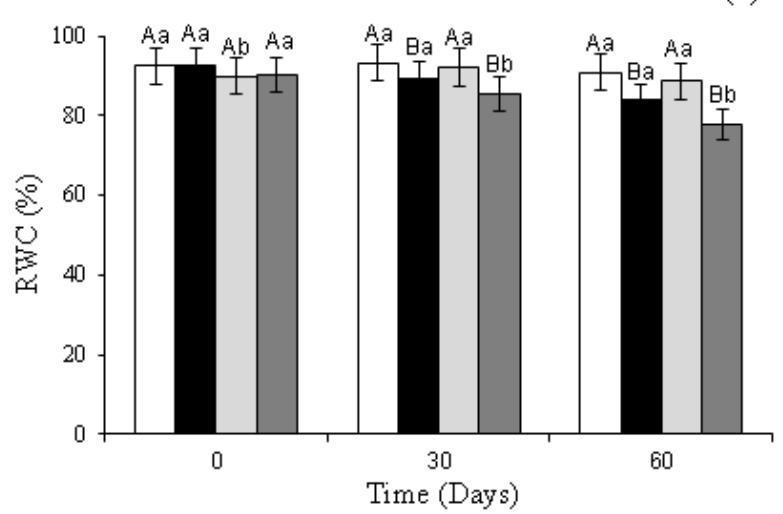

Figure 4 - Leaf water potential (A) and leaf relative water content (B) in two sugarcane genotypes under two water regimes (W, well-watered and D, water deficiency) measured at 0,30 and 60 days after treatment imposition (DAT). Means followed by the same letter are not significantly different at 0.05 probability level (Tukey's test). Bars indicate standard error of the mean of four plants.

\section{DISCUSSION}

Water deficit is an important environmental restriction that influences all of the physiological processes involved in the growth and development of the plants. This influence relates to a group of responses that principally affect the plant's gas exchange mechanisms (Lawlor and Tezara 2009; Centritto et al. 2009). These responses were observed in this study. There were gas exchange differences during the water deficit in the HoCP93-776 and TCP02-4587 sugarcane genotypes. During prolonged drought, the HoCP93-776 genotype displayed higher stomatal sensitivity to an increase in vapor pressure deficit, which led to reduced photosynthesis (Fig. 1). This reduction in the photosynthesis was likely due to a reduction in internal carbon (Oliver et al. 2009). Similar responses to stomatal closing were also identified in other $\mathrm{C}_{4}$ plants subjected to water deficit conditions (Araújo et al. 2010). Stomatal closing reduces transpiration, which diminishes the leaf cooling capacity and increases leaf temperature as the leaf continues receiving light. This results in $\mathrm{VPD}_{\text {(leaf-air) }}$ elevations (Shirke and Pathre 2004; Araújo et al. 2010).

An increase in VPD (leaf-air) was not observed in the TCP02-4587 genotype, which maintained a 
constant $\mathrm{VPD}_{\text {(leaf-air) }}$ during the drought period (Fig. 1A), suggesting less stomatal sensitivity to this variable. According to Schulze (1994), plants with little stomatal sensitivity to the $\mathrm{VPD}_{\text {(leaf-air) }}$ possess high water conductivity in the leaves that can compensate for the loss of evaporation in the leaf mesophyll and prevent the occurrence of localized water deficit. The positive correlation between stomatal conductance and transpiration was determined to be in response to the low substrate water availability (Table 1), thus, demonstrating that transpiration was greatly influenced by the stomatal regulation. Similar effects have also been observed in different sugarcane genotypes cultivated under water deficit conditions (Cha-Um and Kirdmanee 2009; Silva and Costa 2009; Endres et al. 2010).

In response to prolonged water deficit, both of the genotypes exhibited very low stomatal conductance values (Fig. 1B). However, only the TCP02-4587 genotype maintained higher transpiration and photosynthesis rates (Fig. 1), suggesting higher stomatal control efficiency. This was observed by the positive correlation of photosynthesis with gs and E (Table 1), which was considered to be a strong adaptive mechanism to water deficit. According to Lawlor and Tezara (2009), during the periods of water shortage, plants keep their stomatas closed in order to maintain favorable turgor pressures, an important characteristic for drought tolerance. Silva and Costa (2009) studied sugarcane in arid conditions and determined that the reduction of stomatal conductance and a higher photosynthetic rate were both physiological mechanisms responsible for drought tolerance in this plant. Conversely, the closing of stomatas during water deficit decreased the intercellular concentration of $\mathrm{CO}_{2}$ in the HoCP93-776 genotype (Fig. 1B and 2A). This caused an accentuated drop in the photosynthesis rate, which confirmed its drought sensitivity. Studies in the sugarcane under water deficit conditions also showed greater reductions in photosynthesis in several genotypes considered to be drought sensitive (Machado et al. 2009; Silva and Costa 2009; Rodrigues et al. 2009; Graça et al. 2010). During the period of water scarcity, the TCP02-4587 genotype displayed an increased concentration of internal $\mathrm{CO}_{2}$, resulting in a better photosynthetic capacity.

Reductions in the internal $\mathrm{CO}_{2}$ concentration at the sites of carboxylation site often result in photosynthetic limitations (Lawlor and Tezara
2009). The opposite is also true (i.e., elevated $\mathrm{Ci}$ contributes to the linear increase of photosynthesis until its maximum point). Increases beyond the maximum point cannot occur due to $\mathrm{CO}_{2}$ saturation and the limitation of Rubisco regeneration capacity (Ghannoum 2009; Galmés 2011). According to Galmés et al. (2011), a direct effect of stomatal conductance on the Rubisco enzyme is improbable. Instead, the effect is mediated by the reduction in $\mathrm{CO}_{2}$ availability. This reduction in $\mathrm{CO}_{2}$ induces Rubisco deactivation, which limits the photosynthesis because of the plant's necessity to maintain partially closed stomates to avoid dehydration during drought conditions.

Carboxylation efficiency was correlated with stomatal conductance (Table 1). A high $\mathrm{Ci}$ value associated with a low stomatal conductance would indicate a decrease in the $\mathrm{Pn} / \mathrm{Ci}$ ratio in sugarcane (Machado et al. 2009; Endres et al. 2010). The $\mathrm{Pn} / \mathrm{Ci}$ can be considered the estimate of Rubisco activity, illustrating its limitations under stress conditions (Niinemets 2009). The TCP02-4587 genotype was more efficient at carboxylation (i.e., this genotype displayed less damage due to water deficit) based on the activity of the Rubisco enzyme, which was the principal enzyme involved in the $\mathrm{CO}_{2}$ capture process (Niinemets 2009; $\mathrm{Vu}$ and Allen Jr. 2009; Galmés et al. 2011). Vu and Allen Jr. (2009) and Saliendra et al. (1996) studied sugarcane subjected to water deficit conditions and identified a reduction in Rubisco activity during stress conditions.

During water deficit, the TCP02-4587 genotype exhibited the highest instantaneous efficiency of water use compared to the HoCP93-776 genotype. This could be confirmed by TCP02-4587's strong positive correlation with photosynthesis and stomatal conductance (Table 1), indicating that stomatal closing in this genotype reduced the loss of water from the leaf and, thus, led to an increase in water use efficiency. According to Chaves and Oliveira (2004), during the initial establishment of water deficit, the stomatal conductance decreases faster than the photosynthetic assimilation of carbon, resulting in an elevation in WUE. Silva and Costa (2009) identified higher WUE values in tolerant sugarcane genotypes during water deficit, indicating that this characteristic was important in the selection of drought-resistant varieties. Other studies also reported a decrease in WUE under water deficit conditions in sugarcane (Cha-Um and Kirdmanee 2008) and maize (Jabeen et al. 2008). 
A higher rate of intrinsic water use efficiency was observed in the TCP02-4587 genotype (Fig. 2 D), for which $\mathrm{WUE}_{\text {intr }}$ exhibited an inverse correlation with gs (Table 1). This was related to the greater reduction in gs than photosynthesis due to stomatal closing and higher carboxylation capacity in response to drought (Gilbert et al. 2011). Generally, plants tend to reduce the stomatal conductance and increase their photosynthetic rate in response to an increased $\mathrm{CO}_{2}$ concentration. Therefore, the $\mathrm{WUE}_{\text {intr }}$ increase enables the absorption of carbon due to reduced water loss (Farquhar et al. 1989).

Machado et al. (2009) reported that sugarcane genotypes subjected to water deficit conditions during different phenological phases did not display alterations in their intrinsic efficiency of water use during the initial growth phase; however, there was a reduction in $\mathrm{WUE}_{\text {intr }}$ during the maximum growth phase and an accumulation of sucrose with smaller reductions was observed in the drought-tolerant genotype. From a physiological perspective, a high $\mathrm{WUE}_{\text {intr }}$ value is traditionally considered an improvement mechanism that improves the productivity and survival in dry environments (Centritto et al. 2009; Gilbert et al. 2011).

The maximum photochemical efficiency of photosystem II was slightly reduced in HoCP93776 during water deficit. The values were 0.78 in TCP02-4587 and 0.77 in HoCP93-776. This indicated that no damage was detected in the photosynthetic apparatus while exposing the plants to stress. However, Silva et al. (2011) reported an $F v / F m$ ratio value of 0.73 in the HoCP93-776 genotype when it underwent water scarcity under field conditions. According to Maxwell and Johnson (2000), values of less than 0.75 indicated a state of stress and, therefore, a reduction in the plant's photosynthetic potential. Silva et al. (2007) stated that the capacity to maintain a high $\mathrm{Fv} / \mathrm{Fm}$ ratio during water stress could indicate a high efficiency of radiation use, possibly by carbon assimilation reactions. More severe $F v / F m$ reductions that resulted in values below 0.7 were demonstrated in sugarcane genotypes susceptible to water limitation conditions (Silva et al. 2007; Graça et al. 2010; Silva et al. 2011).

The estimated chlorophyll content was maintained at an average of 40 (SPAD index) for TCP024587 , which suggested a higher capacity to keep the leaf area more green to conserve the photosynthetic pigments during drought conditions
(Torres Netto et al. 2005). The SPAD index decreased to 30.62 (Table 3) under the same conditions for the HoCP93-776 genotype, reaffirming its sensitivity to drought. These results were in agreement with the results of Silva et al. (2011) who reported SPAD index values below 40 in sugarcane genotypes sensitive to water deficit. According to Torres Netto et al. (2005), SPAD index below 40 indicated the beginning of a chlorophyll deficiency, which affected the photosynthetic process. This parameter was considered to be a good indicator of disturbances in the plants affected by environmental factors.

Although the $F_{v} / F_{m}$ ratio indicated that no damage was detected in the photosynthetic machinery, the decreasing trend in the positive correlation between the photosynthetic pigments and photosynthesis in the HoCP93-776 genotype showed that the water deficit caused structural alterations in the photosystem II photosynthetic pigments. This was possibly reflected in the destabilization of the photosystem II reaction center, or decreased photosynthetic capacity in sugarcane. These demonstrated that the photosynthetic system damage was enhanced in the HoCP93-776 genotype, further demonstrating its higher sensitivity to drought. The degradation of chlorophyll is one of the consequences of stress that can be the result of photoinhibition and decreased photosynthetic efficiency among other cellular processes, such as cellular division and expansion (Dhanapackiam and Ilyas 2010).

Chlorophyll $a$ and $b$ content, as well as the total chlorophyll content, were higher in the TCP024587 genotype (Table 3). Jangpromma et al. (2010a) observed high levels of chlorophyll in drought resistant genotypes compared to drought susceptible genotypes. This observation was also observed in maize (Jabeen et al. 2008). Variations of the loss of chlorophyll content in sugarcane subjected to drought conditions were also observed in other studies (Cha-Um and Kirdmanee 2009; Jangpromma et al. 2010b).

During the water deficit period, the TCP02-4587 genotype maintained high water potential, while the HoCP93-776 genotype displayed a marked reduction $(-1.9 \mathrm{MPa}$ versus $-2.4 \mathrm{MPa}$, respectively) (Fig. 4A). Field studies found $\Psi_{\mathrm{w}}$ values ranging from $-0.5 \mathrm{MPa}$, under well-watered conditions to -2 MPa under drought conditions (Koonjah et al. 2006; Smit and Singels 2006). Endres et al. (2010) reported $\Psi_{\mathrm{w}}$ values between 1.8 to $-2 \mathrm{MPa}$ in sensitive varieties of sugarcane 
subjected to water deficit and $-1.5 \mathrm{MPa}$ in tolerant varieties. Therefore, the foliar water potential was efficient at indicating the water state of the plants and differentiating the genotypes.

Due to the low water availability in the substrate, a positive correlation between $\Psi \mathrm{w}$, stomatal conductance and photosynthesis in both genotypes was observed (Table 1). Similar effects were demonstrated in different sugarcane genotypes cultivated under water deficit conditions in the field (Smit and Singels 2006; Endres et al. 2010). It could be inferred that the TCP02-4587 genotype provided better drought adaptations under the present experimental conditions. This could be explained by a possible osmotic adjustment that occurred during water deficit (Jamaux et al. 1997). During the water deficit period, the HoCP93-776 genotype had a low relative leaf water level value at $77.8 \%$, whereas the TCP02-4587 genotype reached $83.8 \%$ (Fig. 4B). The maintenance of the RWC in the TCP02-4587 plants may be the result from protoplasts being hydrated for a longer time period during water shortage conditions. This may also be an indicator of the degree to which the tissues and cells are hydrated, which is a crucial factor for optimal physiological functioning (Begg and Turner 1976). Silva et al. (2011) determined average RWC values from $73 \%$ to $79 \%$ for sensitive sugarcane genotypes and RWC values from 85 to $87 \%$ for tolerant genotypes under water deficit conditions in the field. This confirmed that tolerant plants possessed higher capacity to save water during the drought period. Silva et al. (2007); Rodrigues et al. (2009) and Graça et al. (2010) also observed a small RWC reduction in the tolerant genotypes, with an average RWC above $80 \%$. According to Graça et al. (2010), the decreased relative water content stimulates an adjustment of the photosynthetic capacity to tolerate the changes in water availability. This study illustrated that the TCP02-4587 genotype maintained relatively high RWC values during water restriction, thereby indicating drought tolerance in this genotype.

\section{CONCLUSIONS}

The TCP02-4587 genotype was more tolerant to water deficit during the initial phase of development than the HoCP93-776 genotype. This characteristic was attributed to TCP02-4587's high capacity to economize water in its leaves, a higher leaf water potential, a higher efficiency of stomatal control, a higher efficiency in the use of water, a higher intrinsic efficiency of water use, a higher carboxylation efficiency and a higher photosynthetic capacity. Therefore, due to variations in the physiological responses between the genotypes, further studies should be performed concerning these variables in variety improvement programs to develop water deficit tolerant varieties.

\section{REFERENCES}

Amalraj RS, Selvaraj N, Veluswamy GK, Rananujan RP, Muthurajan R, Palaniyandi M, et al. Sugarcane proteomics: Establishment of a protein extraction method for 2-DE in stalk tissues and initiation of sugarcane proteome reference map. Electrophoresis. 2010; 31: 1959-1974.

Araújo SAC, Vasquez HM, Campostrini E, Torres Netto A, Deminicis BB, Lima ES. Características fotossintéticas de genótipos de capim-elefante anão (Pennisetum purpureum Schum.), em estresse hídrico. Acta Scient Anim Sci. 2010; 32: 1-7.

Begg JE, Turner NC. Crop water deficits. Adv Agr. 1976; 28: 161-217.

Bussab WO, Morettin PA. Estatística básica. 3rd. ed. Atual, São Paulo, 1986.

Centritto M, Lauteri M, Monteverdi MC, Serraj R. Leaf gas exchange, carbon isotope discrimination, and grain yield in contrasting rice genotypes subjected to water deficits during the reproductive stage. J Exp Bot. 2009; 60: 2325-2339.

Cha-Um S, Kirdmanee C. Effect of osmotic stress on proline accumulation, photosynthetic abilities and growth of sugarcane plantlets (Saccharum Officinarum L.). Pak J Bot. 2008; 40: 2541-2552.

Cha-Um S, Kirdmanee C. Proline accumulation, photosynthetic abilities and growth characters of sugarcane (Saccharum officinarum L.) plantlets in response to iso-osmotic salt and water-deficit stress. Agric Sci China. 2009; 8: 51-58.

Chaves MM, Oliveira MM. Mechanisms underlying plant resilience to water deficits: prospects for watersaving agriculture. J Exp Bot. 2004; 55: 2365-2384.

Dhanapackiam S, Ilyas MHM. Effect of salinity on chlorophyll and carbohydrate contents of Sesbania grandiflora seedlings. Indian J Sci Techn. 2010; 3: 64-66.

Endres L, Silva JV, Ferreira VM, Barbosa GVS. Photosynthesis and water relations in Brazilian sugarcane. The Open Agr J. 2010; 4: 31-37.

Farquhar GD, Sharkey TD. Stomatal conductance and photosynthesis. Ann Rev Plant Physiol. 1982; 33: 317-345. 
Galmés J, Ribas-Carbó M, Medrano H, Flexas J. Rubisco activity in Mediterranean species is regulated by the chloroplastic $\mathrm{CO}_{2}$ concentration under water stress. J Exp Bot. 2011; 62: 653-665.

Ghannoum O. $\mathrm{C}_{4}$ photosynthesis and water stress. Ann Bot. 2009; 103: 635-644.

Gilbert ME, Zwieniecki MA, Holbrook NM. Independent variation in photosynthetic capacity and stomatal conductance leads to differences in intrinsic water use efficiency in 11 soybean genotypes before and during mild drought. $J$ Exp Bot. 2011; 62: 28752887.

Graça JP, Rodrigues FA, Farias JRB, Oliveira MCN, Hoffmann-Campo CB, Zingaretti SM. Physiological parameters in sugarcane cultivars submitted to water deficit. Braz J Plant Physiol. 2010; 22: 189-197.

Hemaprabha G, Nagarajan R, Alarmelu S. Response of sugarcane genotypes to water deficit stress. Sugar Tech. 2004; 6: 165-168.

Jabeen F, Shahbaz M, Ashraf M. Discriminating some prospective cultivars of maize (Zea mays L.) for drought tolerance using gas exchange characteristics and proline contents as physiological markers. Pak J Bot. 2008; 40: 2329-2343.

Jamaux I, Steinmetz A, Belhassen E. Looking for molecular and physiological markers of osmotic adjustment in sunflower. New Phytol. 1997; 137: 117-127.

Jangpromma N, Kitthaisong S, Lomthaisong K, Daduang S, Jaisil P, Thammasirirak S. Proteomics analysis of drought stress-responsive proteins as biomarker for drought-tolerant sugarcane cultivars. Am J Biochem Biotech. 2010a; 6: 89-102.

Jangpromma N, Songsri P, Thammasirirak S, Jaisil P. Rapid assessment of chlorophyll content in sugarcane using a SPAD chlorophyll meter across different water stress conditions. Asian J Plant Sci. 2010b; 9: 368-374.

Koonjah SS, Walker S, Singels A, Van Antwerpen R, Nayamuth AR. A quantitative study of water stress effect on sugarcane photosynthesis. Proc South Afr Sugar Tech Ass. 2006; 80: 148-158.

Lawlor DW, Tezara W. Causes of decreased photosynthetic rate and metabolic capacity in waterdeficient leaf cells: a critical evaluation of mechanisms and integration of processes. Ann Bot. 2009; 103: 561-579.

Lichtenthaler HK. Chlorophylls and carotenoids: Pigments of photosynthetic biomembranes. Methods Enzymol. 1987; 148: 350-382.

Machado RS, Ribeiro RV, Marchiori PER, Machado DFSP, Machado EC, Landell MGA. Respostas biométricas e fisiológicas ao déficit hídrico em canade-açúcar em diferentes fases fenológicas. Pesq Agropec Bras. 2009; 44: 1575-1582.

Maxwell K, Johnson GN. Chlorophyll fluorescence: a pratical guide. J Exp Bot. 2000; 51: 659-668.
Mccormick AJ, Cramer MD, Watt DA. Culm sucrose accumulation promotes physiological decline of mature leaves in ripening sugarcane. Field Crops Res. 2008; 108: 250-258.

Monneveux P, Rekika D, Acevedo E, Merah O. Effect of drought on leaf gas exchange, carbon isotope discrimination, transpiration efficiency and productivity in field grown durum wheat genotypes. Plant Sci. 2006; 170: 867-872.

Niinemets U, Díaz-Espejo A, Flexas J, Galmés J, Warren CR. Importance of mesophyll diffusion conductance in estimation of plant photosynthesis in the field. J Exp Bot. 2009; 60: 2271-2282.

Oliver RJ, Finch JW, Taylor G. Second generation bioenergy crops and climate change: a review of the effects of elevated atmospheric $\mathrm{CO}_{2}$ and drought on water use and the implications for yield. $G C B$ Bioenergy. 2009; 1: 97-114.

Ramesh P, Mahadevaswamy M. Effect of formative phase drought on different classes of shoots, shoot mortality, cane attributes, yield and quality of four sugarcane cultivars. J Agron Crop Sci. 2000; 185: 249-258.

Rodrigues FA, Laia ML, Zingaretti SM. Analysis of gene expression profiles under water stress in tolerant and sensitive sugarcane plants. Plant Sci. 2009; 176: 286-302.

Saliendra NZ, Meinzer FC, Perry M, Thom M. Associations between partitioning of carboxylase activity and bundle sheath leakiness to $\mathrm{CO}_{2}$, carbon isotope discrimination, photosynthesis, and growth in sugarcane. J Exp Bot. 1996; 47: 907-914.

Schulze ED. The regulation of plant transpiration: interactions of feedforward, feedback and futile cycles. In: Schulze ED, editor. Flux control in biological systems: From enzymes to populations and ecosystems. San Diego: Academic Press; 1994. p. 203-235.

Shirke PA, Pathre UV. Influence of leaf-to-air vapour pressure deficit (VPD) on the biochemistry and physiology of photosynthesis in Prosopis juliflora. $J$ Exp Bot. 2004; 55: 2111-2120.

Silva ALC, Costa WAJM. Varietal variation in stomatal conductance, transpiration and photosynthesis of commercial sugarcane varieties under two contrasting water regimes. Trop Agr Res Ext. 2009; 12: 97-102.

Silva MA, Da Silva JAG, Enciso, J; Sharma V; Jifon J. Yield components as indicators of drought tolerance of sugarcane. Sci Agric. 2008; 65:620-627.

Silva MA, Jifon JL, Da Silva JAG, Sharma V. Use of physiological parameters as fast tools to screen for drought tolerance in sugarcane. Braz J Plant Physiol. 2007; 19: 193-201.

Silva MA, Jifon JL, Sharma V, Da Silva JAG, Caputo MM, Damaj MB, et al. Use of physiological parameters in screening drought tolerance in sugarcane genotypes. Sugar Tech. 2011; 13: 178-184. 
Silva MA, Santos CM, Arantes MT, Pincelli RP. Fenologia da cana-de-açúcar. In: Crusciol CAC, Silva MA, Rossetto R, Soratto RP, editors. Tópicos em ecofisiologia da cana-de-açúcar. Botucatu: FEPAF; 2010. p. 8-22.

Smit MA, Singels A. The response of sugarcane canopy development to water stress. Field Crops Res. 2006; 98: 91-97.

Torres Netto A, Campostrini E, Oliveira JG, BressanSmith RE. Photosynthetic pigments, nitrogen, chlorophyll $a$ fluorescence and SPAD-502 readings in coffee leaves. Sci Hort. 2005; 104: 199-209.
$\mathrm{Vu}$ JCV, Allen Jr, L. Growth at elevated CO2 delays the adverse effects of drought stress on leaf photosynthesis of the C4 sugarcane. J Plant Physiol. 2009; 166: 107-116.

Yordanov I, Velikova V, Tsonev T. Plant responses to drought, acclimation, and stress tolerance. Photosynthetica. 2000; 38: 171-186.

Received: June 29, 2012; Accepted: July 02, 2013. 